\title{
Eugenio Montejo o de poetizar sobre el fracaso como una manera de estar en el mundo
}

Asunción Rangel López

Universidad de Guanajuato

Resumen

En "El alfabeto del mundo", el venezolano Eugenio Montejo intenta restablecer la unión entre el hombre y la naturaleza; en este poema, en particular, se advierte su propensión por descifrar el orden secreto del cosmos y se pone en evidencia su conciencia, como poeta moderno, de la imperfección del lenguaje, incluido el poético. La palabra, entonces, está imposibilitada para decirlo todo, para abarcarlo todo, tarea que, sin embargo, busca realizar afanosamente el sujeto lírico. En el artículo, además, se describe de qué manera aparece poetizado el mito de Orfeo y cómo hay una inclinación a incorporar el universo mítico a la esfera de comprensión y explicación del hombre y su mundo. Estos tópicos, a propósito de su poética, guardan una profunda relación con ciertos presupuestos del movimiento romántico.

Palabras clave: poesía latinoamericana, poesía moderna, Romanticismo, mito de Orfeo. 


\section{Abstract}

In the poem "Alphabet of the world", the Venezuelan Eugenio Montejo seeks to restore the relationship between man and nature, indeed, his desire to decipher the secret order of the cosmos in the interest of writing poetry about it. It also makes clear his conscience Montejo as modern poet, inability to achieve full or just the word and prayer that the lyrical subject swore in an effort to say everything, to cover everything. It also describes about the presence of the Orpheus myth in some moments of his poetry, his propensity to return to the mythical world. These features, as noted in the article show a deep connection to various topics of the Romantic movement.

Keywords: Latin American poetry, modern poetry, Romanticism, Orpheus myth.

\section{I}

G n La máscara, la transparencia. Ensayos sobre poesia hispanoaEmericana (1975) el crítico y también poeta Guillermo Sucre sostiene ciertas ideas, en torno a la poesía moderna, que en mi opinión resultan capitales para el acercamiento a algunos momentos de la poesía del venezolano Eugenio Montejo (1938-2008). Se trata de una serie de apreciaciones que giran alrededor de determinados presupuestos de la tradición romántica.

De acuerdo con Sucre, desde el Romanticismo, en algunos poetas hay una propensión por reconciliar naturaleza e historia, universo e individuo; éste es, sin lugar a dudas, uno de los grandes intentos de la poesía moderna. Sucre alude en su libro, en diferentes momentos y a propósito de la obra de diversos poetas latinoamericanos, a tópicos y problemáticas que acusan una profunda relación con el movimiento romántico, el cual, para decirlo con Isaiah Berlin, generó efectos incalculables por su acción trans- 
formadora, tanto en la vida como en el pensamiento occidental. Se trata de un movimiento de tal calibre que nada ha sido igual después del mismo (2000).

Sobre la obra de José Antonio Ramos Sucre —otro venezolano sobre quien Montejo no tiene empacho en declarar y hacer manifiesta su filiación y admiración literaria-, por ejemplo, el autor de La máscara, la transparencia... indica: "¿No se siente que detrás de cada texto de Ramos Sucre hay un Texto, que detrás de su obra está la Obra, y que toda ella parece desarrollarse como los sucesivos avatares de la Palabra? Pero si muchos de sus poemas son paráfrasis o glosa (vocablo que él mismo empleó), lo son desde un presente de la escritura: reescribir es volver a la experiencia original" (1975: 74). Si bien, en esta observación se advierte que el trabajo poético de Ramos Sucre se distingue por un constante revisitar sus propios poemas en aras de perfeccionarlos, de volver a lo ya escrito introduciendo cambios, me parece que cuando el crítico habla de volver a la experiencia original está aludiendo a otra de las consignas o presupuestos que distinguieron a ciertos poetas románticos. Me refiero a la vuelta a la experiencia original que describe Novalis en sus Himnos a la noche.

En el Canto V, el poeta alemán se refiere al antiguo mundo, así como al declive del mismo, de la siguiente manera: antes de la decadencia del mundo antiguo, los "ríos, árboles y animales tenían sentido humano". En ese tiempo mítico, los dioses y los hombres vivían en el "regazo de una diosa" (en Marí, 1979: 149): la naturaleza. Pero fue un "solo pensamiento, un pavoroso sueño" - la muerte, la angustia - (150), lo que generó la escisión entre el hombre y ese mundo vetusto:

Los dioses desaparecieron con su séquito - Quedó la Naturaleza inerte y solitaria. El número árido y la estricta medida la ataron con feroces cadenas. Igual que en polvo y viento se deshizo en oscuras palabras la inmensurable exuberancia de la vida. Huyó la 
fe evocadora y su divina compañera, la imaginación que todo lo transforma y todo lo hermana (151).

El poeta se duele de la huída de los dioses y se duele más aún de la separación entre el hombre y la naturaleza, y reprocha que el pensamiento ilustrado haya pretendido referirse a ella mediante el "número árido" y, más todavía, que haya osado sujetarla con "feroces cadenas" al raciocinio. En la cita de Novalis también se pone de manifiesto el estatuto privilegiado del que goza la imaginación, la cual será la vía idónea para restablecer ese nexo entre naturaleza y hombre. El romántico considera que la modernidad ha acentuado la distancia entre el hombre y la naturaleza, entre el hombre y la divinidad, y será la poesía el medio propicio para restablecer esa armonía perdida, por restablecer o volver, para decirlo con Guillermo Sucre, a la experiencia original. Cabe destacar que, a propósito de la mención al idealismo mágico de Novalis, éste es también una tentativa de "hablar en el lenguaje de la naturaleza".

Volver a la experiencia original, de esta manera, acusa una profunda relación, además de con el trabajo de reescritura, con soñar que se retoma el principio, que se vuelve a empezar, que se recrea (Deleuze, 2005: 16). Esto, en el terreno del Romanticismo, no quiere decir otra cosa que señalar la urgencia de la vuelta del hombre a ese mundo primario y primigenio, al mundo del mito. La vía idónea para semejante empresa, como ya ha quedado señalado, no será otra más que la poesía, mediante la cual el poeta intenta "hablar en el lenguaje de la naturaleza", integrarse a ella, descifrar su orden y su secreto.

Beatriz González Moreno lo explica en Lo sublime, lo gótico y lo romántico: la experiencia estética en el romanticismo inglés (2007):

Schelling (1775-1854) recoge lo que será una constante en la percepción de la Naturaleza por los románticos: el mito del anima mundi, tal y como lo concibe Platón en su Timeo. Es decir, el uni- 
verso se entiende como un ser viviente con alma y razón, donde todos y todo está integrado en perfecta armonía; y esto es posible porque la propia alma humana ha sido creada con los restos de la substancia que había servido para crear el alma del mundo. [...]

Esta postura filosófica lleva a Schelling a afirmar que "la Naturaleza debe ser el espíritu invisible, el espíritu, la Naturaleza invisible" (1996: 110). De esta forma, leer en los caracteres de la Naturaleza significa conocer todos los misterios de la naturaleza humana. [...] El paisaje circundante se convierte en un gran libro abierto, plagado de grafismos. El rostro del mundo, según expone maravillosamente Michel Foucault en el capítulo "La prosa del mundo", dentro de Las palabras y las cosas (Les motes et les choses) (1966), está cubierto de blasones, de caracteres, de cifras — de jeroglíficos, decía Turner. Crollius, como Paracelso —el que será modelo de Víctor-, sugiere mirar la naturaleza detenidamente y descifrar sus entrañas (40-41).

Esta introspección al mundo natural, como echa de verse, no implica una mera descripción del "paisaje circunstante", sino una profunda y detenida meditación del mismo en aras de descifrar las entrañas de la naturaleza que, análogamente, se corresponde con la naturaleza humana. Para decirlo de una vez: poetizar sobre un río, sobre el trópico o los pájaros es, asimismo, dar a la naturaleza un corazón humano y al hombre un alma natural. Eugenio Montejo, como se intenta mostrar en este artículo, es un poeta que busca en la naturaleza el aliado más fervoroso para consumar este sueño de totalidad que los románticos profesaron.

\section{II}

"No he escrito ensayos en el sentido cabal de la palabra. De tanto en tanto suelo escribir comentarios a propósito de algunas obras, tratando de esclarecer lo que encuentro en ellas de sugestivo en términos de simpatía o de desacuerdo" (Montejo, 2006: 354). Esta 
apostilla de Montejo sobre algunos de sus comentarios acerca de la poesía de Carlos Pellicer, el pensamiento poético de Octavio Paz o, por mencionar otro ejemplo, sus aproximaciones a José Antonio Ramos Sucre, alcanza a convertirse en una suerte de declaración de principios poéticos si se considera que en su manera de situarse frente a la obra ajena persiste la búsqueda de aquellos rasgos de comunión o de posible conversación —en el sentido de la palabra latina conversare- y el también permisible y natural desacuerdo entre sus actitudes frente a la poesía, los temas de los que se ocupa, en suma, de su particular lectura que hace del mundo y las variaciones o coincidencias que encuentra en la obra de otros escritores.

$\mathrm{Al}$ referirme a una declaración de principios poéticos o a su particular lectura poética que hace del mundo, no hago más que aludir a tan sólo uno de los preceptos en la actitud lectora que Montejo adopta en el momento en que se enfrenta a la obra de otro escritor, y ésta es, en sus palabras, de simpatía o de desacuerdo. Montejo lee y escribe sobre Rafael Cadenas, Juan Calzadilla y Ramón Palomares, escritores de su generación, en aras de entrever aquello con lo que sus actitudes poéticas coinciden o divergen. El propio Montejo describe su manera de leer poesía y escribir acerca de ella, cuando se ocupa de, por ejemplo, la poesía del brasileńo Carlos Drummond de Andrade:

En una memorable conferencia del año 1948, el poeta inglés W. H. Auden, recién fallecido este ańo, al esbozar su concepción de la poesía y de lo que creía primordial en la relación del hombre con la palabra en nuestra época, anotaba a modo de conclusión: "Las cosas que me interesa leer un poema son dos: la primera es técnica: he aquí un aparato verbal, ¿cómo funciona? La segunda es, en un sentido amplio, moral: ¿qué especie de tipo habita este poema? ¿Qué le oculta al lector, qué se oculta a sí mismo?” Cierto, otros intereses pueden concurrir en el ánimo del lector, por ejemplo: ¿qué mundo inaugura esta palabra? ¿Desde cuál zona sensible 
emprende su captación del universo? ¿Se trata de una alta poesía que se propone áreas estéticas limitadas o, a la inversa, es una poesía fatalmente menor, atrapada en la imposibilidad de ambiciones absolutas? ¿Cuáles ecos prolonga, cuáles apenas enuncia como posibles de ser retomados más tarde? De muchas otras indagaciones, intuitivas o sistemáticas, podemos valernos a la hora de encarar el poema. Conviene sin embargo advertir que las dos apuntadas por Auden se encuentran entre las más esenciales (247).

Aquí se advierte qué entiende Montejo por leer en términos de simpatía y de desacuerdo. Las afinidades que señala, en su manera de entender la poesía, tanto con Auden como con Drummond de Andrade, se refieren a aspectos formales, técnicos, relativos al aparato verbal, pero, además, a una serie de rasgos que si bien se revelan a nivel textual tienen que ver con una operación de carácter interpretativo, hermenéutico: qué tipo de sujeto se está construyendo en el poema, qué tipo de realidad —absolutamente ficticia - le está presentando al lector y qué decide decirle y ocultarle, con qué tradiciones dialoga, con qué obras o poemas conversa de manera deliberada y explícita o cifrada. Las reflexiones a propósito del mundo que inaugura la palabra y sobre el asidero sensitivo desde el cual el poema lee el mundo, me parece, exigen al lector un arduo y complejo trabajo de interpretación que ni el propio Montejo, a propósito de Drummond de Andrade, alcanza a resolver en las páginas que dedica a la poesía del brasileño.

De manera análoga, o intentando seguir el mismo espíritu lector de Montejo, el comentario que a continuación se propone, busca poner de realce los puntos de comunión que encuentro entre su poética y algunos motivos señaladamente románticos. Esto no quiere decir, en ningún momento, que la poesía de Montejo es, de manera general romántica, o peor aún, que es un poeta romántico, sino que ésta es una de las tradiciones en las que abrevan algunos momentos de su producción. 
Alfabeto del mundo $(1988,2005)$ forma parte de la copiosa producción de Montejo; en 1976 ya había publicado Algunas palabras, seguido de Terredad (1978), Trópico absoluto (1982), Adiós al siglo XX (1922, 1997), El azul de la tierra (1997), Partitura de la cigarra (1999), Papiros amorosos (2004), Poemas selectos (2004), y las colecciones de ensayos El taller blanco (1938) y La ventana oblicua (1974). Huelga mencionar, asimismo, las ediciones líricas y críticas de sus heterónimos:

Eduardo Polo, autor de Chamario, Sergio Sandoval, autor de la coplas de Guitarra del horizonte, Lino Cervantes, autor de la Caza del relámpago, para no hablar de El cuaderno de Blas Coll presentado por Eugenio Montejo y del libro firmado por Thomas Linden: El hacha de seda, con prólogo y selección de Eugenio Montejo (Castanón, 2009: 558).

En diferentes partes de su obra, Montejo se refiere al lenguaje poético, a la poesía misma, para erigir un encomio, pero también una diatriba, contra la misma. El poema "Alfabeto del mundo" es tan sólo uno de esos momentos. En él, Montejo evidencia, entre otras cosas, su conciencia como poeta moderno de que el lenguaje, incluido el poético, es imperfecto. Quiero decir: se advierte que se sabe inmerso en la tarea infinita de acortar la distancia que media entre lo que las palabras dicen y lo que aspiran decir. De entrada, el título del poema resulta profundamente sugerente: el alfabeto como un conjunto de símbolos empleados en un sistema de comunicación, que atañe al mundo, al cosmos. El lector de este poema, desde el inicio del mismo, está informado de que los asuntos sobre los que se poetizará versan, precisamente, sobre los modos y maneras que emplea el universo para comunicar algo. Considero significativo observar el empleo de la contracción del para referirse al alfabeto como una materia perteneciente al cosmos, es decir, 
como un asunto del que habla el mundo y no como un tema del que se ocupará, por decirlo de alguna manera, un yo humano. Es el mundo quien hablará a través de sus símbolos, de su lenguaje. Es de esperarse, por ello, que el poeta dé cuenta de esas maneras de ser del lenguaje del universo.

El propio sujeto lírico se declara, al inicio del poema, imposibilitado para acceder a esta habla cósmica, y más aún, para dar cuenta de ella en su escritura:

En vano me demoro deletreando
el alfabeto del mundo.
Leo en las piedras un oscuro sollozo,
ecos ahogados entre torres y edificios,
indago la tierra por el tacto
llena de ríos, paisajes y colores,
pero al copiarlos siempre me equivoco.

Destaca, en estos versos iniciales, la actitud indagatoria del sujeto lírico con respecto al habla cósmica: se trata de una actividad lenta, demorada que, paradójicamente, culmina en una tarea vana, por no decir inútil e ineficaz. Esta pronunciación paulatina de los símbolos del cosmos, es además de carácter interpretativo: se trata, como lo indica el sujeto lírico, de leer y de indagar, empresa que culmina en copiarlos en, como lo dirá unos versos más adelante, "mi cuaderno". Su tarea se inscribe, así, en el ámbito adivinatorio de lo oscuro y dificultoso de entender. Esta idea se refuerza con la lectura del "oscuro sollozo" de las piedras. El deseo de absoluto, de Totalidad - para decirlo con el Romanticismo- no termina con la osada empresa del sujeto lírico de abarcarlo todo, de saberlo todo sobre el habla del mundo, ya que su exploración sobre el mismo - leer, indagar, copiar - va de un elemento tan nimio como una piedra, hasta las torres y los edificios, los ríos, los paisajes y 
los colores de la tierra. Ir de la piedra a los colores de la tierra no es otra cosa que la propensión, que va in crescendo, por referirse a la diversidad y pluralidad del orbe. Cabe señalar la variedad de los elementos a los que se refiere, esto es, componentes tanto del ámbito meramente natural — la piedra, los ríos, el paisaje—, como del ámbito, por decirlo de alguna manera, urbano - las torres, los edificios. De esta manera, el sujeto lírico está participando de dos esferas que, de entrada, parecen irreconciliables: la urbe y, su natural contracara, el bosque, el trópico, la selva.

Una vez que el sujeto lírico ha declarado su incapacidad, más bien, su equívoco al copiar en su cuaderno las maneras de ser del lenguaje del cosmos, introduce una suerte de consigna que habría de fructificar en la consecución de su empresa:

Necesito escribir ciñéndome a una raya sobre el libro del horizonte.

Dibujar el milagro de estos días que flotan envueltos en la luz y se desprenden en cantos de pájaros.

En estos versos se advierte de qué manera se habrá de proceder, no para dar cuenta a cabalidad del alfabeto del mundo, sino para intentar acercarse a la palabra justa, íntegra. El procedimiento implica "escribir" y "dibujar". Ahora bien, la primera de las tareas, el trabajo de escritura, se inscribe en un ámbito opresivo y asfixiante, tal como lo indican el primer y segundo versos: "ciñéndome a una raya / sobre el libro del horizonte". Esta suerte de sujeción, sin embargo, se contrasta con un elemento radicalmente opuesto que supone el quebrantamiento de cualquier atadura, ya que si bien el sujeto lírico debe poetizar ceñido a una raya, esto se hará encima o acerca de un elemento de amplitudes infinitas e incalculables como lo es el horizonte. Huelga mencionar que en el primer ver- 
so del fragmento arriba citado se procede yendo de un elemento nimio o minúsculo - una raya o, en este caso, un verso- a uno de rasgos espaciosos y descomunales —el horizonte, el poemario.

La segunda de las tareas que se impone el sujeto lírico es dibujar. En este momento del poema la atadura que implica la conciencia del equívoco en la búsqueda de la palabra cabal, me parece, se ha resquebrajado. El sujeto lírico dibuja en esos tres versos aquello que precisamente se le revela ante los ojos: los días envueltos en luz, metáfora alargada mediante la cual se convierte a los mismos días en canto de pájaros. El verbo "dibujar" se ejecuta conforme se va avanzando en la lectura del poema, y esto sucede, precisamente, cuando se despliega la potencialidad del horizonte visto como un libro. Me permito recuperar, en esta línea, el presupuesto del Romanticismo que versa sobre considerar el paisaje como un gran libro abierto. Lo que ahí lee el sujeto lírico de este poema de Eugenio Montejo son los caracteres, las cifras de la naturaleza, las cuales intentará dibujar para dar cuenta de ese "milagro" que está presenciando.

Los siguientes siete versos de "Alfabeto del mundo" revelan un determinado tiempo y espacio - absolutamente ficticios - en que se sitúa la mirada del sujeto lírico. Antes, ha indicado al lector que está presenciando "el milagro de los días". Esta metáfora, o reunión de un elemento abstracto - como lo es el milagro- con uno concreto, en cuanto a la temporalidad — los días-, muestra que la visión poética que se nos está presentando está inserta en una serie temporal, asunto que se reafirma con el uso de la conjunción "cuando" en los siguientes versos:

Cuando en la calle los hombres que deambulan de su rencor a su fatiga, cavilando, se me revelan más que nunca inocentes. Cuando el tahúr, el pícaro, la adúltera, los mártires del oro o del amor 
son sólo signos que no he leído bien, que aún no logro anotar en mi cuaderno.

La anáfora del primer y cuarto versos citados, "cuando", sin embargo, no implica una sucesión en el tiempo, quiero decir, se trata de señalar el suceso, el milagro de los días, pero a la vez, de suspenderlo para describirlo en términos de espacio. Aparece entonces la calle y los hombres que transitan por ella. Este tránsito es errático y meditabundo, como se indica en "los hombres que deambulan" y “cavilando". Una vez más, Montejo emplea sustantivos concretos — la calle_ en conjunción con sustantivos abstractos —el rencor, la fatigaj. Esta última metáfora es profundamente sugerente si se considera que Montejo es capaz de observar movimiento en donde aparentemente no existe: señala el desplazamiento en la calle, pero también la traslación del rencor a la fatiga. La marcha vagabunda de los hombres que ve el sujeto lírico se le aparece, más bien, se le revela inocente. De esta manera, aflora en el poema un contrapunto en cuanto al tratamiento de lo observado, es decir, el ojo poético de Montejo es capaz de advertir la inocencia en la fatiga, en el rencor. Esto, como se lee en el verso "que aún no logro anotar en mi cuaderno", no promete, sin embargo, que se logrará dar el salto de la observación a la transcripción de lo observado.

Ahora bien, de la generalidad de los hombres que deambulan por las calles, el yo lírico enuncia o se refiere a ciertos "personajes" de la urbe: el tahúr, el pícaro, la adúltera. Esto, me parece, reafirma que el ojo poético de Montejo selecciona, ora elementos de índole absolutamente prodigiosa —el horizonte, la luz, los pájaros_-, ora elementos abyectos, marginales —el tahúr, el pícaro, la adúltera. Los elige, no para denostar o encomiar alguno de ellos, sino para conjuntarlos y ubicarlos en la misma esfera. De ahí que sobre los seres viles o despreciables hable en términos de simpatía; los llama "los mártires del oro y del amor". Todos estos elementos, como se indica en el siguiente verso, corresponden a un sistema de signos 
- y no debe de olvidarse que el poema versa, precisamente, sobre el alfabeto del mundo- de los cuales el sujeto lírico no puede dar cuenta a cabalidad en su cuaderno, porque no los ha "leído bien". A riesgo de repetir una idea que he venido sosteniendo en estas páginas, me parece fundamental insistir en que el poeta es consciente del menoscabo, de la imperfección del lenguaje, incluido el poético.

Entendido de esta condición, Montejo expresa su deseo por acortar la distancia que media entre lo que las palabras dicen y lo que aspiran decir. Los siguientes versos de "Alfabeto del mundo" no son otra cosa que manifestación de esa tensión entre su apetencia de decirlo todo, de abarcarlo todo, y de saberse imposibilitado de lograrlo:

Cuánto quisiera al menos un instante

que esta plana febril de poesía

grabe en su transparencia cada letra:

Este grupo de versos que cierra el poema son una suerte de plegaria, una súplica que el poeta profiere con el ánimo de ubicarse o de conseguir un instante privilegiado en el cual la palabra lograría transitar del estado febril al del sosiego de la transparencia. Al referirse a un instante, el sujeto lírico está aludiendo a una porción brevísima del tiempo en que la revelación poética le será dada. Se trata de un intervalo fugaz, efímero, pero que tendrá consecuencias de índole perpetua, eterna, como se ve en el tercer verso cuando alude a su intención de grabar cada letra del alfabeto del mundo. Me parece que esto acusa una profunda relación con el Romanticismo. Un poeta de la talla de Novalis emplea la noción de lo efímero para referirse a la unión o a la conciliación de los opuestos. En sus fragmentos, habla, por ejemplo, de que en la combustión "se produce, en el mismo instante de la penetración, una violenta repulsión y una atracción simultáneas" (1996: 172). El instante, de 
esta manera, reúne repulsión y atracción. De manera análoga, en el poema de Montejo es el instante el momento privilegiado en que febrilidad —entendida como turbación — se complementará con la transparencia —entendida como serenidad—, como se explica a continuación.

El pronombre demostrativo del segundo verso, "esta”, permite decir que el sujeto lírico se está refiriendo, sin más, a los propios versos que escribe. En ese verso, también describe algunos rasgos de su propia escritura. Se trata de una plana febril, metáfora que se inserta en un contexto de desasosiego en el que vive el poeta por su incapacidad de alcanzar la palabra justa y cabal. Pero la febrilidad no sólo puede ser entendida en términos de desazón, me parece que en esa manera de adjetivar, Montejo da cuenta, además, del ardor, de la violencia y del arrebato que supone la gana y el deseo de escribir. En esta tesitura, hay que destacar en este segundo verso una situación en que priva el estremecimiento, lo agitado, y que persiste un anhelo por ubicarse en un polo contrario: en la pasividad y claridad que implican la transparencia. Asimismo, mediante el verbo grabar del tercer verso, se pone en evidencia la intención del poeta por captar y fijar profundamente lo que a continuación va a enumerar:

la o del ladrón, la t del santo el gótico diptongo del cuerpo y su deseo, con la misma escritura del mar en las arenas, la misma cósmica piedad que la vida despliega ante mis ojos.

Al sujeto lírico le interesa grabar — como ha dicho en el verso que antecede a los arriba citados - las letras y, particularmente, la $o$ y la $t$, no de cualquier palabra, sino precisamente las de ladrón y santo. Se advierte aquí, una vez más, la propensión en ciertos momentos de la poesía de Montejo, por reunir los contrarios, por congregar 
en la poesía aspectos y personajes disímiles. En el segundo verso, "el gótico diptongo del cuerpo y su deseo", incorpora una dimensión de la existencia humana que no había sido poetizado o tomado en consideración en los versos antecedentes de "Alfabeto del mundo", a saber: el aspecto erótico. Tal pareciera que en el poema de Montejo se va desplegando una acuciosa observación del mundo que va desde las piedras, las torres, los edificios, los pájaros, el tahúr, el pícaro; observación que incluye la descomposición de las palabras con las que solemos referirnos los seres del mundo: la $o$ de ladrón, la $t$ de santo. Estos elementos se inscriben en diferentes y diversas esferas de la existencia humana: la naturaleza, la urbe, los seres viles y marginados, y los que, al contrario, gozan de un lugar privilegiado por la supuesta perfección de su conducta. Faltaba por incorporar, me parece, el deseo.

El verso "el gótico diptongo del cuerpo y su deseo" se integra a esta visión de la totalidad que el sujeto lírico del poema persigue afanosamente. Ahora bien, Montejo es un poeta que lidia una lucha - desgarradora, pero también placentera - en la búsqueda de la palabra exacta. De ahí que llamar gótico al diptongo del cuerpo no sea fútil. Primero, cabe recordar que el diptongo, esencialmente, une dos vocales diferentes; segundo, adjetivarlo como gótico, me parece, indica la propensión de Montejo por dar luz a ciertas zonas de la existencia humana, quiero decir: dotar a la dimensión erótica de rasgos que liberen al sujeto de lo opresivo, de la cerrazón. Cabe decir, en esta línea, que lo gótico — sobre todo en la arquitectura - se caracteriza por la predilección de espacios abiertos y luminosos, que buscan acercar, como sucede en las iglesias que arquitectónicamente se adscriben a esta tendencia, al hombre con la divinidad. Se trata nuevamente de la conciliación de esferas o tópicos diametralmente opuestos; conciliación que irradia desde el sustantivo diptongo hasta el adjetivo gótico.

Sobre los tres versos que cierran el poema, me permito repetir 
una de las ideas de Américo Ferrari que ya he anotado en otro momento, porque la considero precisa y contundente en cuanto a la poética que se urde en la obra de Eugenio Montejo. Para Ferrari, en la obra del poeta venezolano, existe un:

[...] anhelo o la tentación (expresado por más de un poeta moderno) de abandonar la escritura en palabras, de grabar las letras con la misma escritura del mar en las arenas o con una escritura de piedra: "Alguna vez escribiré con piedras / midiendo cada una de mis frases / por su peso, volumen, movimiento. Estoy cansado de palabras" ("Escritura"). Esto parece imposible. Pero el poeta persigue tercamente ese imposible, empeñándose, de poema en poema, en inventar un lenguaje más fiel a las músicas del mundo, más natural” (37).

La consciencia de la imposibilidad por alcanzar la palabra cabal o justa y la plegaria que el sujeto lírico impreca en su afán de decirlo todo, de abarcarlo todo, finaliza en el deseo hecho manifiesto por grabar "con la misma escritura del mar en las arenas / la cósmica piedad / que la vida despliega ante mis ojos." Montejo inventa, como lo seńala Ferrari, un lenguaje propio para emprender la osada tarea de desdeñar su propio alfabeto y ajustarse, más bien, al lenguaje de la naturaleza, al alfabeto del mundo, en donde los símbolos, los sintagmas, los fonemas poco tienen que ver con el sistema de signos que cotidiana y poéticamente se emplean para referirse al mundo. De ahí que Montejo siempre esté en pugna con la palabra, porque su poesía es una que permanece, incansablemente, en aras de hablar mediante el lenguaje de la naturaleza.

\section{III}

“¿Qué especie de tipo habita este poema?", se pregunta Eugenio Montejo a través de Auden. En aras de seguir el espíritu lector del poeta venezolano, e intentando responder a su propio cuestio- 
namiento en el trasluz de su poesía, me parece que la especie de tipo - de sujeto- que habita "Alfabeto del mundo", es uno que intenta establecer una relación humana con la naturaleza: la poesía en Montejo es una manera de descifrar el sentido y el orden secreto de la propia naturaleza, del cosmos.

Este sujeto, que intenta hablar en el "lenguaje de la naturaleza", busca además incorporarse a ese mundo vetusto y primigenio que alguna vez el hombre habitó. Me refiero, sin más, a la esfera mítica, al natural adversario del pensamiento ilustrado y mecanicista. En la obra de Montejo, no son pocos los momentos en que se advierte y resuena esta urgencia por la restitución del mito en las maneras de comprensión y explicación de lo humano. "Orfeo", poema que abre la colección titulada Muerte y memoria (1972), da cuenta de ello:

Orfeo, lo que de él queda (si queda), lo que aún puede cantar en la tierra, ¿a qué piedra, a cuál animal enternece? Orfeo en la noche, en esta noche (su lira, su grabador, su cassette), ¿para quién mira, ausculta las estrellas? Orfeo, lo que en él sueña (si sueña), la palabra de tanto destino, ¿quién la recibe ahora de rodillas?

Solo, con su perfil en mármol, pasa por nuestro siglo tronchado y derruido bajo la estatua rota de una fábula.

Viene a cantar (si canta) a nuestra puerta, ante todas las puertas. Aquí se queda, aquí planta su casa y paga su condena, porque nosotros somos el Infierno. 
Las conjunciones "si" contenidas en los versos primero, séptimo y treceavo, en opinión de Ferrari:

[...] están cargadas de una terrible significación; así como hemos perdido la certeza de Dios [...], hemos perdido la certeza del canto. No sabemos siquiera si queda algo de Orfeo, si sueńa, si canta. Si canta es a fin de cuentas como si estuviera mudo, o peor aún, tartamudo, como dice el poeta en "Esta ciudad", pues nadie recibe sus palabras, a nadie enternece. Quizá este Infierno que somos nosotros y en el que se ha quedado el fantasma de Orfeo más que un mundo sin canto es uno en que el canto, mutilado y fatigado, cae inmediatamente en la indiferencia, en el silencio o en la irrisión (Ferrari: 27).

Aunque, efectivamente, "nosotros somos el infierno" y el canto parece no interesar o enternecer a nadie, resuena en los versos de "Orfeo" una suerte de acto de fe en el propio canto. Incluso frente a la indolencia, a la duda sobre quién recibe la palabra "ahora de rodillas", en Montejo persiste cierta propensión por darle al canto un estatuto privilegiado, un asidero de existencia que lo salvaguarda de "nuestro siglo tronchado y derruido". La propia condición dubitativa del "si", a caballo entre la negación y la afirmación, da muestra de ello.

En el ensayo "Poesía en un tiempo sin poesía" (1983), de $E l$ taller blanco, Montejo se ubica como un poeta que vive en el siglo "más huero en espacio vital para la poesía" (185), pero a su vez, expresa una fuerte convicción y certidumbre de que "cualquiera [que] sea el parecer venidero acerca del arte de nuestro tiempo, será de todos modos innegable que cuanto se pudo salvar de la palabra fue mediante una lucha más ardua, aceptando un destino de expósitos" (185). La opinión que le merece al poeta venezolano respecto del ejercicio poético reúne, una vez más, condiciones que se antojan diametralmente opuestas: por una parte el infatigable 
trabajo, la lucha más ardua y desgarradora frente a la palabra poética, y por otra, el abandono, el disponerse expuesto en el mundo, como lo dirá en unos versos de "Poeta expósito" de Alfabeto del mundo: "[...] errando a la intemperie, / mi único padre es el deseo I y mi madre la angustia del huérfano en la tierra” (2005: 60). Lucha y abandono, deseo y angustia, son duplas indispensables en la poética de Montejo, parejas de opuestos que en ningún momento encuentran una resolución que abogue a favor de sólo una; se trata de ambas al unísono, de ambas al mismo tiempo: coincidentia oppositorum.

De manera análoga, con el ánimo de conciliar todas las esferas de comprensión y de existencia humanas, Montejo opta por revisitar el mito de Orfeo. El Orfeo de Montejo, en ese momento de su producción poética, es acompañado de su lira, o de su cassete o grabadora, que no son otra cosa más que los instrumentos, los aparatos de los que se vale el poeta para hacer resonar su canto, su música. Al sustituir la lira por el cassete o la grabadora, Montejo actualiza el mito de Orfeo y deposita en él, sin lugar a dudas, un voto de confianza, un acto de fe — por decirlo de alguna manera — en la vigencia y vitalidad del canto poético, independientemente de la época o el contexto social o histórico en que el poeta ose cantar.

El poema “Orfeo" de 1972 encuentra una suerte de continuación en la obra de Montejo en 1986 en "Orfeo revisitado", de Alfabeto del mundo. La manera de poetizar sobre el esposo de Eurídice, se codea con el tono y acento crítico del poema de 1972. Se trata de una postura desoladora acerca de la pertinencia y vigencia del canto órfico - “Orfear aquí tal vez el hombre puede / sólo para sí mismo en la hora atea, / ante los otros con trucos de ventrílocuo" (Montejo, 2005: 209)_, pero también se advierten un encomio y una urgencia por restituirle su lugar privilegiado en la esfera de la existencia humana, porque el canto, si bien es "tartamudeante y roto y solitario", se aferra en concurrir, en acaecer: 
Orfear, verbo que nos declina su alto ensueño, verbo en milagro del espíritu, cuando tartamudeante y roto y solitario paga en cantos su vida y jura a ciegas que tras sus pasos un ángel musicante va recogiendo los últimos sonidos (209).

En la permuta del sustantivo Orfeo por el verbo orfear, se advierte la propensión por la movilidad, por la ejecución del canto como algo que está siempre en constante movimiento, y circulación, y, sobre todo, orfear como un verbo que carece de persona pero que aloja todas las posibles conjugaciones del mismo. En suma, se trata de la potencialidad de la ejecución del canto. Más aún, el sujeto lírico deposita en ese verbo el "milagro del espíritu", "los últimos sonidos" que un ángel musicante —que no podría ser otro más que el poeta - va recogiendo a su paso.

El llamado de Montejo no podría ser más preciso: la vuelta al mito y al mundo natural, a ese espacio primigenio de la existencia humana, incluso, y sobre todo, en una época en la que la indolencia por el canto de la poesía es casi moneda común. El sujeto que habita la poesía de Eugenio Montejo no podría ser otro que uno que participa de ese sueńo de factura señaladamente romántica. Frente a la sordera de nuestra época, el regreso al mundo vetusto y primigenio — de otros tiempos - es, a final de cuentas, el llamamiento y la prédica de este poeta que clama por la vuelta, para decirlo con uno de sus versos, "a tus dioses profundos" ("Vuelve a tus dioses profundos”, de Terredad, 1978).

En el regreso, en la vuelta a esa experiencia original y primigenia, Eugenio Montejo figura como un poeta que sabe que también volverán el dolor y los desastres, pero también volverán los placeres, el goce de saberse nuevamente inmerso en el gran libro de la naturaleza. La vía primigenia para lograrlo es, como se apuntó, la 
palabra poética. Y la palabra, aunque fuese la del origen, es asimismo la fuerza de la repetición; ésta nunca dice una vez por todas, sino otra vez más, eso ha tenido ya lugar una vez y tendrá lugar una vez más, y siempre de nuevo, de nuevo. $\mathrm{O}$ para decirlo con palabras del propio Nietzsche:

¡Hombre! toda tu vida es como un reloj de arena, que sin cesar es vuelto boca abajo y siempre vuelve a correr; un minuto de tiempo durante el cual todas las condiciones que determinan tu existencia vuelven a darse en la órbita del tiempo. Y entonces volverás a encontrar cada uno de tus dolores y tus placeres, cada uno de tus amigos y tus enemigos y cada esperanza y cada error, y cada brizna de hierba, y cada rayo de luz, y toda la multitud de objetos que te rodean. Este anillo, del cual tú eres un pequeño eslabón, volverá a brillar eternamente (en Savater, 2000: 84).

El incansable llamado de Montejo es una manera de restaurar las fuerzas gastadas en el combate ganado o perdido. El enfrentamiento con el mundo exterior es, sin duda alguna, desgarrador. Pero incluso así, la vocación que no se rinde, la que es fiel a su curiosidad, a su fuerza, promete, como en el caso de este poeta venezolano, que la poesía tiene toda la vida por delante.

\section{Bibliografía}

Argullol, Rafael, 2008, El Héroe y el Único, Acantilado, Barcelona.

Berlín, Isaiah, 2000, Las raices del romanticismo, Henry Hardy (ed.), Silvina Marí (trad.), Taurus, Madrid.

Borgeson Jr., Paul W, 1989, “(Sur)realismo en la poesía venezolana del '58”, en Actas de la Asociación Internacional de Hispanistas, X, pp. 465-475.

Castañón, Adolfo, 2006, "Rumbo a Montejo", en Eugenio Montejo. Geo- 
metria de las horas, una lección antológica, Universidad Veracruzana (Ficción), México.

Curtius, Ernest Robert, 1995, Literatura europea y edad media latina, Margit Frenk y Antonio Alatorre (trads.), FCE, México.

Deleuze, Gilles, 2005, "La isla desierta”, en La isla desierta y otros textos, José Luis Pardo Torío (trad.), Pre-textos, Valencia.

Ferrari, Américo, 2005, "Eugenio Montejo y el alfabeto del mundo", en Alfabeto del mundo, FCE (Tierra firme), México.

González Moreno, Beatriz, 2007, Lo sublime, lo gótico y lo romántico, la experiencia estética en el romanticismo inglés, Ediciones de la Universidad de Castilla-La Mancha, Cuenca.

Marí, Antoni, 1979, El entusiasmo y la quietud. Antología del romanticismo alemán, Tusquets, Barcelona.

Montejo, Eugenio, 2005, Alfabeto del mundo, FCE (Tierra Firme), México.

,2006, Eugenio Montejo. Geometria de las horas, una lección antológica, Universidad Veracruzana (Ficción), México.

Novalis, 2007, Himnos a la noche, Jorge Arturo Ojeda (trad.), Fontamara, México.

, Himnos a la noche, 1985, José María Malverde (trad.), Rafael Argullol (pról.), Icaria, Barcelona.

, 1996, La enciclopedia, Fernando Montes (trad.), Fundamentos, Madrid.

Paz, Octavio, 1984, Los hijos del limo. Del romanticismo a la vanguardia, Seix Barral, México. ,2003, El arco y la lira, FCE, México.

Savater, Fernando, 2000, Idea de Nietzsche, Ariel, Barcelona.

Sucre, Guillermo, 1985, La máscara, la transparencia: ensayos sobre poesía hispanoamericana, FCE, México. 